\title{
A geopolítica da política externa do pragmatismo ecumênico responsável (1974-1979): o papel do Ministério das Relações Exteriores
}

\author{
The geopolitics of the foreign policy of the \\ ecumenical responsible pragmatism (1974-1979): \\ the Role of the Ministry of Foreing Affairs
}

\section{CAIO CURSINI}

\section{INTRODUÇÃO}

Em 1974, a ascensão de Ernesto Geisel à presidência do Brasil durante o regime militar levou à adoção de uma forma de política externa denominada de pragmatismo ecumênico responsável, encabeçada principalmente por Azeredo da Silveira, Golbery do Couto e Silva e o próprio presidente. Esta postura do governo brasileiro versava sobre as formas de condução principalmente da política exterior do país, de modo a enrijecer o caráter nacionalista brasileiro concomitantemente à manutenção do respeito ao capitalismo norte-americano, e em detrimento da expansão territorial da União Soviética.

O pragmatismo responsável, como corriqueiramente nomeado, apontava para uma política externa na qual os interesses brasileiros não se submeteriam às pressões estrangeiras, principalmente às dos Estados Unidos, como, inclusive, aponta Spektor (2004). Do ponto de vista externo, ser pragmático referia-se à construção de uma imagem nacional e tomada de decisões por parte dos estadistas brasileiros que buscassem, sobretudo, atingir aos interesses permanentes do Estado, o que afastava, portanto, o espectro de alinhamento automático do governo brasileiro perante a política externa dos Estados Unidos. Sumariamente, segundo Cervo (1994):

Caio Cursini - Doutorando em Geografia com ênfase em Geopolítica na Universidade de São Paulo (USP). Mestre em Geografia pela Universidade de Brasília (UnB). Cursou Graduação em Geografia pela Universidade Federal do Triângulo Mineiro (UFTM). 
o pragmatismo induz a adequação das percepções dos reais interesses nacionais aos desígnios externos, de forma a fazer prevalecer o resultado sobre o conceito, os ganhos concretos e materiais sobre os valores políticos ou ideológicos, a oportunidade sobre o destino, a liberdade de ação sobre o empenho do compromisso, o universalismo sobre as camisas de força dos particularismos, a aceitação sobre a resistência aos fatos. [...] o pragmatismo da política exterior do Brasil produziu dois resultados históricos: o abandono da ideia de construção e o uso da potência para obter ganhos externos e a despolitização, enfim a moralização da conduta (Cervo 1994, 27).

Além disso, uma política externa pragmática, mais do que uma orientação teórica, das relações entre o Brasil e outros Estados-Nações durante esse governo militar, passou a ter um formato consistente que diferia da postura externa brasileira em relação aos governos anteriores, como veremos ao longo deste artigo. Deste modo, a construção da política externa durante Ernesto Geisel caracterizou-se por objetivos bastante claros, que, por conseguinte, não poderiam estar desconectados de uma visão geopolítica na qual a consecução dos objetivos do governo brasileiro estaria atrelada às estratégias de inserção internacional do país.

Em termos práticos, o próprio Ernesto Geisel, diante do primeiro ministro japonês Takeo Miki, expressou da seguinte forma a postura externa do país:

nós procuramos ser pragmáticos e, no relacionamento com outros países, ressaltar os pontos de cooperação e não os de divergência. Acreditamos que a cooperação traz melhores resultados do que o antagonismo. Não somos imediatistas. Ao contrário, visamos ao longo prazo. (Silveira 1976a).

No entanto, embora o pragmatismo responsável tenha sido uma postura explícita e muito debatida entre os internacionalistas e historiadores da política externa brasileira, seria pertinente aventar o caráter geopolítico da inserção internacional do país durante este período. Apoiados em Costa (2008), por geopolítica compreendemos o resultado das interações sobre um composto formado por atores, território e poder, partindo do pressuposto que a geopolítica não se oferece previamente, mas é dinâmica, na medida em que as ações políticas são avaliadas pelos estadistas. Seria equivocado, por exemplo, pressupor que as diretrizes externas em Ernesto Geisel estivessem apartadas de uma clara concepção geopolítica. Deste modo, elevar o Brasil a um grau de potência, considerando esse conceito de acordo com a definição de Wight (2002, 4), "uma potência é um estado moderno e soberano em seu aspecto externo", a delimitação de objeti- 
vos atuais e permanentes para a política externa e a própria execução dos ideais pragmáticos ecumênicos responsáveis nas tratativas internacionais não podem ser dissociados da visão geopolítica, que em última instância sustentava o objetivo final do governo Ernesto Geisel de aumentar o coeficiente de poder do Estado brasileiro no cenário internacional. As análises da conjuntura externa associadas ao espaço geográfico brasileiro, realizadas pelos estudiosos da Escola Superior de Guerra (ESG), evidenciam a relação entre a geopolítica e a política externa brasileira. Tomando como exemplo um relatório da ESG datado de 1978, as condições que moldavam as ações diplomáticas do país eram:

1) A cooperação externa ao desenvolvimento brasileiro, quando aceitável, apenas suplementará o esforço interno. O desenvolvimento é problema nacional a ser obtido com o empenho das forças vivas da nação; 2) $\mathrm{O}$ desenvolvimento científico e tecnológico é fator fundamental para o progresso nacional acelerado; 3) A emergência do país como potência econômica mundial; 4) A dependência significativa do país, quanto à tecnologia e produtos externos, inclusive equipamentos militares (Madruga 1978).

Portanto, o que propomos neste artigo é destacar o caráter geopolítico das tratativas internacionais do governo brasileiro durante o período do pragmatismo responsável, buscando por meio do conteúdo de documentos históricos evidenciar o liame entre geopolítica e política externa. A documentação analisada pode ser encontrada na Biblioteca da Escola Superior de Guerra do Rio de Janeiro e no Centro de Pesquisa e Documentação de História Contemporânea do Brasil (CPDOC). Os arquivos examinados aludem ao período entre 1974 a 1979, ou seja, o período referente ao governo Ernesto Geisel.

Propomos que a geopolítica está intrínseca à política externa do referido período. Para tanto, dividimos as análises em dois momentos. Inicialmente, realizamos uma leitura no âmbito regional, especificamente do Cone Sul do continente sul-americano, por entendermos que a documentação verificada tenha relevância por trazer interessantes perspectivas geopolíticas. Em seguida analisamos a política externa brasileira no continente africano, asiático e centro americano. Ressaltamos que foram utilizados para as análises documentos históricos dos atores políticos brasileiros, como o próprio Ernesto Geisel, Azeredo da Silveira e Golbery do Couto e Silva o que nos levou à seleção de alguns eventos políticos em detrimento de outros. Esses documentos são telegramas, notas em geral e recomendações que foram trocadas entre esses atores da política brasileira e estão disponibilizadas no CPDOC. 


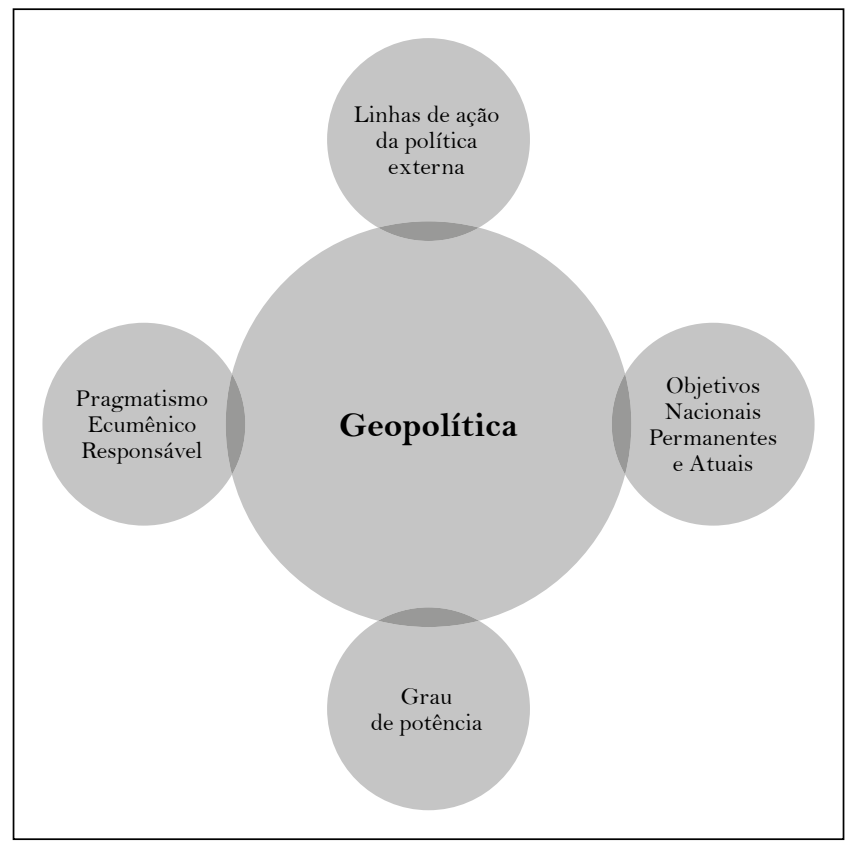

Esquematização 1 - A Política Externa em Ernesto Geisel e a Geopolítica

Fonte: Elaboração própria.

\section{O PRAGMATISMO RESPONSÁVEL E A POLÍTICA EXTERNA BRASILEIRA NO CONE SUL}

Existem, deste modo, formas de analisar qualquer documentação, como pontua Aróstegui (2006). Deste modo, é necessário verificar a validade do conteúdo documental, assim como confrontá-lo com informações materiais de outros campos da ciência a fim de validar o conteúdo histórico. É neste sentido que a geopolítica e as relações internacionais municiam a pesquisa histórica, uma vez que estes campos de estudo permitem a verificação documental daquilo que é encontrado nos arquivos de política externa brasileira.

Por conseguinte, é necessário destacar que o governo de Ernesto Geisel (1974-1979) foi um governo militar de orientações nacionalistas, ${ }^{1}$ o qual buscou, em um contexto internacional de retração do poder de influência dos Estados Unidos, ${ }^{2}$ consolidar os desvios dos eixos da política externa brasileira, levando assim a que as diretrizes externas do país considerassem a China comunista não somente como um Estado soberano, mas como um 
parceiro comercial; o mesmo caso ocorre com a declaração do sionismo como uma forma de racismo, colocando o Brasil num cenário favorável em relação aos países árabes. O fato é que Ernesto Geisel, em conjunto com Azeredo da Silveira (1974-1979), seu ministro das relações exteriores, buscou um posicionamento externo autônomo e universalista, alterando a concepção de alinhamento automático dos governos militares anteriores. Como universalismo pode-se entender a busca pela variação dos parceiros diplomáticos, desviando-se a política externa do eixo que congrega os Estados Unidos e a Europa. O universalismo dialoga com a autonomia quando concebe que o desenvolvimento e o poder do país só serão implementados e multiplicados com o distanciamento dos alinhamentos automáticos em relação aos países desenvolvidos. Ainda, segundo Lessa (1998, 31 ):

sendo entendida como fator de ampliação da liberdade diplomática, a construção do universalismo, desde os seus primórdios, foi temperada por boa dose de pragmatismo, outro elemento característico da práxis diplomática brasileira e fundamental para a compreensão da Política Exterior do Brasil no século XX.

É neste sentido que, partindo do levantamento bibliográfico de Nazário (1983) e Vizentini (1998), a política externa em Ernesto Geisel teria marcadamente os seguintes objetivos: a) fortalecimento das relações diplomáticas com os países do entorno regional brasileiro (América do Sul); b) aproximação de países não hegemônicos na Ásia e na África; c) estabelecimento de uma relação próxima, porém autônoma, com os Estados Unidos e países da Europa Ocidental; d) restabelecimento de relações com os países do bloco comunista.

Todos estes objetivos foram estabelecidos de acordo com a orientação "pragmática" da política externa deste governo, que moldava suas decisões a partir dos interesses nacionais. A possibilidade de ganho de autonomia internacional em decorrência das dificuldades enfrentadas pelos Estados Unidos tanto no cenário interno quanto no externo propiciava um ambiente favorável ao governo brasileiro na busca da consecução de seus objetivos internacionais.

A primazia por uma política externa dinâmica e participativa do governo brasileiro com os países do seu entorno geográfico devem ser interpretadas como consequência das orientações pragmáticas do governo Ernesto Geisel a fim de fortalecer o poder do Estado brasileiro no contexto sul-americano. Para tal, as relações na região da Bacia do Rio da Prata eram fundamentais, como destacam Mello (1996) e Child e Kelly (1988).

Neste sentido, a relação entre o governo brasileiro e o paraguaio pode exceder o âmbito político de conversações entre Ernesto Geisel e o 
então presidente paraguaio Stroessner, de modo que a materialização das estruturas territoriais, isto é, da infraestrutura entre Brasil e Paraguai, era essencial não somente para a solidificação das relações destes dois países, mas também para a manutenção da proeminência regional do Brasil em detrimento da Argentina. Essa afirmação funda-se na interpretação de alguns documentos de Azeredo da Silveira, que nos apontam que a relação brasileira com o Paraguai era importante, pois apoiava-se numa rivalidade velada entre Brasil e Argentina. É nesse sentido que Silveira endereçava à embaixada brasileira em Assunção um telegrama com o seguinte trecho:

não podemos permitir, entretanto, que na tentação invencível em que se debate o Governo paraguaio, de seguir, ainda que inconscientemente, uma política pendular entre seus vizinhos, o que o leva a criar todo um clima artificial que venha a justificar suas inclinações de momento, que se ponha em dúvida a correção, a seriedade e a maturidade do Governo Brasileiro, e que se sirvam dessas dúvidas para obter vantagens nossas e de Buenos Aires (Silveira 1976b).

Esta disputa delegava ao governo paraguaio a possibilidade de praticar uma política pendular, como observado no Relatório da Escola Superior de Guerra:

no campo econômico, pratica o Paraguai a "Política Pendular", procurando desenvolver-se economicamente à base do auxílio que poderá obter de seus vizinhos do Prata, interessados no potencial energético do Rio Paraná e Paraguai, com vistas ao seu aproveitamento hídrico (Escola Superior de Guerra 1975).

A constatação desta orientação da política externa paraguaia não era uma característica recente do país guarani, e o conhecimento desta orientação de Stroessner pelo governo brasileiro levou Ernesto Geisel e Azeredo da Silveira a uma série de ações em direção ao Paraguai, como é possível constatar na documentação:

a) Plano de Ação em Favor do Paraguai; b) Estrada EncarnaciónPuerto Presidente Stroessner; c) Implantação de uma usina siderúrgica no Paraguai; d) Acordo para se evitar bitributação; e) Desenvolvimento da região do Alto Paraná; f) Entrepostos de depósito Franco; g) Interconexão Ferroviária; h) Ligação rodoviária Brasília-Assunção; i) Melhoria das condições de navegabilidade do Rio Paraguai (Silveira 1974).

A intenção do governo brasileiro em se aproximar do Paraguai evidencia que este país representava um dos vértices de maior importância para a estratégia brasileira de consolidação do Brasil como Estado proeminente 
na América do Sul. O desenvolvimento da região do Alto Paraná, área limítrofe com o Brasil, denota a relação entre o território e poder imbuídas nas discussões da política externa brasileira. De fato, é possível verificar a inauguração de agências bancárias no Paraguai durante o governo Ernesto Geisel, como demonstra Silveira (1977), assim como constatar diversos estudos de viabilidade para a implantação de uma rede de transportes que integrassem o Brasil e o Paraguai (Ministério dos Transportes 1975).

A relação entre a integração do território brasileiro ao paraguaio está inserida numa lógica na qual a dinamização das relações econômicas e logísticas teria um impacto na política externa dos dois países. Como apontado por Pereira (2007), a relação entre a estruturação do território brasileiro ao longo da história aponta que a consolidação de uma rede de comunicação e defesa no interior do país, além de enrijecer as recém-estabelecidas fronteiras do Brasil, cooptou relações com os países do entorno continental brasileiro. ${ }^{3}$

Assim, do mesmo modo que a relação entre o território e o poder pode ser demonstrada na relação entre o Brasil e o Paraguai, é na Bolívia, área fundamental no continente sul-americano, como destacado por Travassos (1935), que o governo de Ernesto Geisel procuraria estabelecer vínculos políticos e econômicos evidentes. Assim, como indica o relatório da ESG, a prioridade da política externa do país andino era o estabelecimento de uma rota que lhe garantisse o acesso ao mar:

apenas uma questão distingue a atuação diplomática da Bolívia, que procura ressaltar em todos os foros internacionais sua mediterraneidade e a ânsia de ver solucionado seu problema marítimo através da reaquisição de uma faixa de terra litorânea do Pacífico (Escola Superior de Guerra 1975).

Os objetivos brasileiros em relação à Bolívia consideravam enfaticamente o problema do isolamento boliviano, de modo a fazer desta condição uma forma de atrair o país andino para a zona de influência brasileira, como já observava Travassos (1935), assim como fazem acreditar as próprias correspondências entre os ministérios da política externa desses dois países. A política externa brasileira durante o governo Ernesto Geisel, em direção à Bolívia, evidencia o aspecto colaborativo com este país, notabilizando, assim, o interesse brasileiro em pender a política externa boliviana para o lado brasileiro. É neste sentido que Azeredo da Silveira sugeriu a Ernesto Geisel a facilitação do livre trânsito de mercadorias do país governado por Banzer Suárez (Silveira 1974b), além de estabelecer a concessão de 50 milhões de dólares em crédito, exportação de material bélico brasileiro para a Bolívia, implantação de ferrovias e financiamento de siderúrgicas (Silveira 1974c). 
Esta política de atração do governo boliviano em direção ao Brasil, além de expor o caráter participativo regional do Ministério das Relações Exteriores no Brasil, também exterioriza a necessidade de o governo brasileiro contrapor as posições argentinas na região sul-americana. A Argentina, país de proporções territoriais e econômicas concorrentes ao Brasil no continente, também buscava certa proeminência regional e procurava conter os objetivos geopolíticos do governo brasileiro.

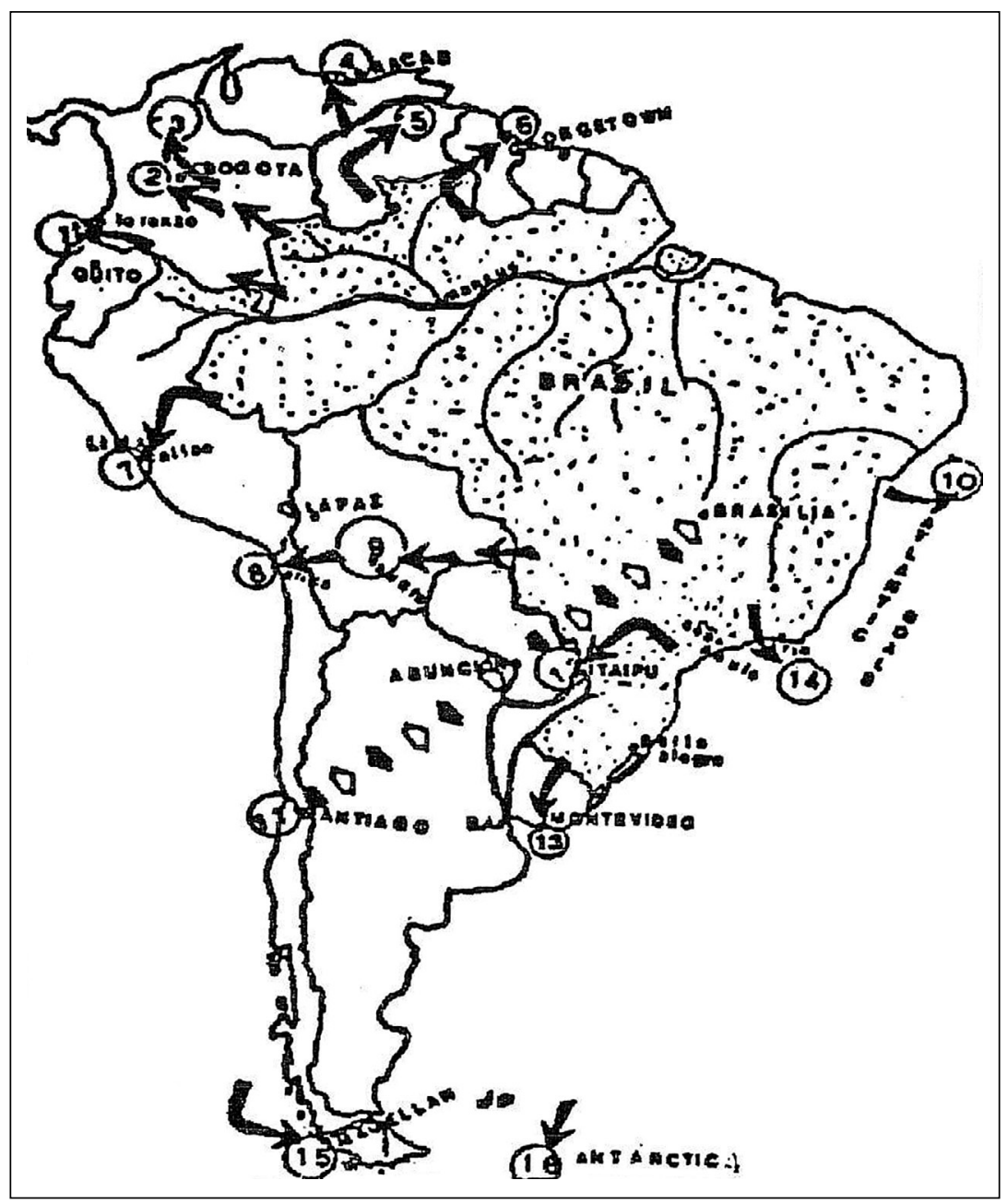

Mapa 1 - Visão Argentina dos Objetivos Geopolíticos Brasileiros.

Fonte: Geopolítica. no $37(1988,16)$ (apud. Mello 1996, 149). 
Esta rivalidade pode ser verificada, por exemplo, na venda de armas de empresas brasileiras para a Bolívia, notabilizando a preocupação do governo brasileiro em equiparar-se ao governo de Buenos Aires no fornecimento de material bélico para os países sul-americanos. Em trecho da correspondência, Azeredo da Silveira informa Ernesto Geisel sobre o andamento de uma negociação de armamentos entre o governo brasileiro e o boliviano, já iniciada no governo Garrastazu Médici. ${ }^{4}$ No trecho, é possível ler:

[...] o Ministério da Defesa Boliviano, ressaltam: a) os resultados qualificados como "ótimos", das provas realizadas com munição brasileira em campo de tiro de La Paz; b) as dificuldades mencionadas quanto a eventual financiamento da exportação e afirmação de que a Argentina oferece melhores vantagens (Silveira 1974d) (grifo nosso).

O atrelamento das relações brasileiras com o Paraguai e a Bolívia tinha como escopo confrontar o interesse argentino na Bacia Hidrográfica do Rio da Prata, principalmente no que tange à questão da instalação da Usina de Itaipu. Azeredo da Silveira, em 1974, expõe a questão a Ernesto Geisel e enfatiza o esforço argentino em considerar o uso das águas dos rios internacionais uma questão supranacional, como estabelecido na Conferência Pan-Americana de Montevidéu em 1933 em que, segundo a interpretação argentina, o uso das águas internacionais deveria ser submetido ao entendimento unânime dos países ribeirinhos. Contrário a esta posição, segundo o Ministro das Relações Exteriores do Brasil, tanto a Bolívia quanto o Paraguai haviam expressado seus posicionamentos em favor da proposição brasileira de proteção à soberania nacional e liberdade de utilização dos recursos naturais do país (Silveira 1974f).

O que as relações entre o Brasil e os países do Cone Sul evidenciam é a preocupação brasileira com a balança de poder na América do Sul. Embora a efetivação de um "projeto" geopolítico ao nível governamental, como aquele elaborado por Travassos (1935) possa ser colocada em dúvida, assim como também não é possível transportar a leitura de Golbery do Couto e Silva sem ressalvas àquilo que era desenhado na política externa brasileira de Ernesto Geisel, é importante que se diga que Golbery participou diretamente do processo de formulação e decisão da política externa brasileira, e durante o governo Ernesto Geisel era notório o papel de mediação e opinativo do geopolítico brasileiro junto ao Ministério das Relações Exteriores, como se evidencia nos documentos de Couto e Silva (1974). Por outro lado, consideramos superficial e insuficiente a concepção de que a geopolítica somente é identificada através de "projetos" geopolíticos teorizados e aplicados às diretrizes políticas de um país. Consideramos que a visão realista das relações entre os Estados pressupõe uma organização espacial interna 
do país a fim de garantir a manutenção e/ou a multiplicação do poder do Estado no cenário internacional. ${ }^{5}$ Esta relação entre o realismo, a política externa e a geopolítica clássica é observada por Becker:

apoiada nos princípios do paradigma do realismo político, a geopolítica reforça a tradição político-geográfica dos estudos focados no Estado. Mais do que isso, de fato, os estudos geopolíticos clássicos reconhecem o Estado como o único protagonista das relações internacionais, depreendendo-se desse reconhecimento a ideia de que o Estado é a única fonte de poder Becker (2012b, 147).

A política externa brasileira durante o pragmatismo responsável de Ernesto Geisel apresentou evidentes sinais de uma busca para o fortalecimento da imagem do país no cenário regional, assim como junto a EstadosNações anteriormente considerados pouco relevantes para a diplomacia brasileira. Como exemplo, podemos citar a participação brasileira em países da África, assim como o reconhecimento do Estado chinês e a afirmação do sionismo como uma prática racista. Partindo dessas estratégias, o Brasil propunha-se a elevar seu coeficiente de participação internacional, coadunando, portanto, com a visão de Vizentini (1998) de que os governos militares no Brasil nunca desprezaram a ótica de tornar o país uma potência.

A relação brasileira com os países sul-americanos exalta o aspecto geopolítico implícito que, embora esteja relacionado a um pensamento estratégico prévio das diretrizes políticas do país, não foi exposto num manual de geopolítica ou notabilizado nas obras de conhecidos geopolíticos brasileiros. Isto não significa, no entanto, que geopolíticos brasileiros não tenham tido influência sobre as estratégias externas do país, mas que supomos que as diretrizes construídas ao interior do Ministério das Relações Exteriores também sejam fontes inegáveis de conhecimento geopolítico prático. A relação brasileira com os países da América do Sul, principalmente aqueles localizados na bacia do Rio da Prata, leva-nos à ótica de que a geopolítica, um campo de estudo que versa sobre as relações entre o poder, os atores políticos e o território, é constituída e refletida também pelo Ministério das Relações Exteriores. É neste sentido que concordamos com Becker (2012a) quando a autora afirma que:

a geopolítica não está dada, ela é construída hoje, no atual período histórico, pelo trabalho humano tanto material quanto intelectual e, assim produzida, tem movimento e abertura para o indeterminado, que é essencialmente político.

A colocação da autora possui integral sentido ao nível da política externa brasileira, na medida em que esta não pode ser encerrada à sim- 
plória análise da posição do Estado no mundo, ou da relação entre localização e poder, tópico muito debatido e ponderado por geopolíticos brasileiros como M. Mattos (1977), C. Silva (1981), T. Castro (1999), e estrangeiros como H. Mackinder (1904) e J. Mahan (1897). A perspectiva de Becker (2012a) de que o poder do Estado está primeiramente inscrito na complexa relação entre os atores do poder hegemônico confirma-se nas evidências documentais do governo Ernesto Geisel. Excedendo a perspectiva regional, é notória a prolongada ponderação entre Golbery do Couto e Silva, Azeredo da Silveira, Ernesto Geisel e diversos ministros deste governo no reconhecimento e restabelecimento das relações diplomáticas com a China comunista, no prolongamento das atividades exteriores entre o governo brasileiro e os países do Oriente Médio e África, na procura de estabelecer uma política externa autônoma e pragmática na qual os estabelecidos interesses do Estado brasileiro não se diluíssem diante do poder dos países da Europa Ocidental e principalmente dos Estados Unidos. O delineamento da política externa do país estava relacionado às ideias que perpassavam por esses atores da política brasileira: o reconhecimento da China, por exemplo, foi o resultado da materialização de ideias convergentes naquele período político. Com isso, queremos dizer que as ações da política externa brasileira estavam dentro de um quadro de ideias pensado a priori, partindo do pressuposto que os estadistas devem conhecer o país e o seu território; por conseguinte, as ações da política externa partem de fundamentos teóricos que podem ser chamados de geopolíticos, pois partem de uma leitura territorial do Estado por seus atores políticos - no caso, os ministros e o próprio presidente.

Ao tomarmos como referência os principais geopolíticos do período, logo notaremos que a aproximação em relação aos países sul-americanos não é uma tese muito difusa, quando a encontramos como em Travassos (1935) pouco se tem sobre como ocorreria essa conexão entre o Brasil e seus vizinhos. Do mesmo modo, Silva (1981) aventa sobre algumas perspectivas regionais, inserindo também o Brasil como uma referência continental. Os geopolíticos desse período frequentemente tratavam o assunto como algo a ser aplicado à política.

No entanto, é perceptível uma lacuna entre a geopolítica e aquilo que era construído no Ministério das Relações Exteriores. Se partirmos da perspectiva que as diretrizes da política externa brasileira possuíam fundamentos geopolíticos, pois estava fundamentada em concepções de poder, território, relações entre atores políticos internacionais e a posição do Brasil no mundo, abrimos uma ótica de que há uma geopolítica na política exterior que independe da literatura. Assim, o pragmatismo ecumêni- 
co responsável era antes de tudo uma concepção geopolítica de Ernesto Geisel e seu grupo político.

\section{O PRAGMATISMO ECUMÊNICO RESPONSÁVEL E A GEOPOLÍTICA BRASILEIRA NO MUNDO}

A relação entre a política externa brasileira e o desenvolvimento econômico do país não foi uma singularidade do governo Ernesto Geisel. A inserção de objetivos desenvolvimentistas na agenda da política externa brasileira pode ser identificável já no início do século XX com Barão do Rio Branco, e, mais evidentemente, a partir do Estado Novo, com Getúlio Vargas, como destaca Moura (1980). Como aponta Cervo (2003; 2008), é possível identificar, entre os anos de 1930 até o final da década de 1980, uma conduta externa brasileira sob a perspectiva do paradigma desenvolvimentista ${ }^{6}$ de perspectiva econômica, que versava sobre a necessidade da expansão industrial a fim de superar as barreiras ao desenvolvimento da América Latina ao final da década de 1940. A consolidação das concepções desenvolvimentistas ocorreu a partir da instituição da Comissão Econômica para a América Latina e Caribe (Cepal) em 1948, num contexto em que as condições de subdesenvolvimento da América Latina contrastavam com a concessão de créditos estadunidenses aos países europeus devastados pela Segunda Guerra Mundial.

Tendo Celso Furtado como principal expositor, as ideias desenvolvimentistas permeariam a política externa brasileira e impulsioná-las-iam em direção a estratégias que buscassem, a partir de um expediente externo limitado pelas pressões das grandes potências, adquirir alternativas para o desenvolvimento econômico brasileiro. É neste sentido que a política externa de Ernesto Geisel — valendo-se da parcial retração da hegemonia dos Estados Unidos, que na década de 1970 começava a demonstrar incapacidade na continuação da Guerra do Vietnã e no cenário interno era abalado pelo escândoalo de Watergate - foi desenvolvida sob a chamada ótica pragmática, mas também responsável (pragmatismo responsável). $\mathrm{O}$ governo brasileiro buscava, portanto, um posicionamento do país que não rompia ou criava demasiados atritos com o governo de Washington, ao mesmo tempo em que enfatizava algumas demandas próprias da pasta de Azeredo da Silveira.

Assim que assumiram o governo, Ernesto Geisel e Azeredo da Silveira buscaram estabelecer relações exteriores mais próximas com diversos países da África, Oriente Médio e América Central, incluindo alguns sob o regime comunista como China, Cuba e Angola. Este redirecionamento da política externa brasileira era guiado pelo aumento do preço do petróleo, 
como aponta Lessa (1994), e também pela concepção de que o alinhamento automático da diplomacia brasileira em relação aos Estados Unidos e Europa Ocidental constituía um óbice ao desenvolvimento do país, já que os interesses internacionais destes Estados muitas vezes divergiam daqueles brasileiros, o que impulsionava as relações externas brasileiras com países do terceiro e segundo mundo. ${ }^{7}$

É neste sentido que, no documento de 1974, é possível verificar o caráter estratégico do reconhecimento da República Popular da China pelo governo brasileiro. No fragmento da correspondência de Azeredo da Silveira ao presidente, lê-se que:

desde que a RPC (República Popular da China) regressou ao convívio diplomático internacional, e, particularmente, após seu ingresso na $\mathrm{ONU}$, vem ela adotando posições e defendendo princípios que coincidem com posições e princípios defendidos pelo Brasil [...] tem apoiado o direito dos países de estenderem o seu mar territorial, o de protegerem os seus recursos naturais, certas teses favoráveis ao desarmamento e outras que igualmente apoiamos (Silveira 1974c).

Deste modo, o processo de reconhecimento da China não estava somente conectado a procedimentos políticos, mas a relações estratégicas contidas na aproximação brasileira em direção a um país considerado uma potência mundial - o que nos sugere um quadro geopolítico em que, antes de tudo, a visão geopolítica brasileira era consoante com o posicionamento chinês. O reatamento com o governo de Pequim, portanto, deve ser considerado a partir de uma visão geopolítica bem definida do governo Ernesto Geisel, na qual a política externa era um mecanismo primordial para a consecução tanto dos objetivos econômicos como territoriais.

Neste sentido, a aproximação brasileira com alguns países do bloco comunista respondia aos objetivos da política externa do país, que eram sustentados por uma visão geopolítica na qual o Estado brasileiro deveria zelar pela sua posição e potência no cenário internacional. O estabelecimento de numerosas relações comerciais entre os empresários brasileiros e os chineses denotam o caráter econômico do reatamento entre Brasil e China, além da importância estratégica que o país asiático representava para os objetivos permanentes do Estado brasileiro (Silveira 1974h).

A partir de uma concepção realista do cenário internacional, os atores da política externa brasileira definiam as ações externas do país de acordo com uma bem delimitada estrutura geopolítica. Isto quer dizer que as ações da política externa brasileira durante o pragmatismo responsável podem indicar que o governo brasileiro concebia a política externa como um instrumento de expansão do poder do Estado. Neste sentido, as rela- 
ções brasileiras com os países do Oriente Médio também podem indicar que a política externa procede a partir das condições materiais do espaço territorial de um país.

Assim, no que tocava à relação brasileira com os países produtores de petróleo do Oriente Médio, era necessária uma política externa que garantisse o fornecimento de petróleo ao Brasil, como observa Vizentini (1998). A política pragmática de Ernesto Geisel, portanto, vislumbrava uma estratégia de cooperação e aproximação aos países daquela região, a ponto de considerar o sionismo ${ }^{8}$ uma forma de discriminação em relação ao povo palestino, como apresenta o documento sobre a posição brasileira na XXX Assembleia das Nações Unidas (Silveira 1975a).

As garantias energéticas as quais o governo brasileiro buscava dialogam diretamente com a condição e o papel do Estado brasileiro no cenário global. As medidas de cooperação entre o Brasil e o Iraque, como evidencia o documento de Azeredo da Silveira a Ernesto Geisel, notabilizam o papel que um país produtor de petróleo exercia sobre a política externa brasileira. Deste modo, o documento evidencia que, além de o Iraque constituir-se em um promissor fornecedor de petróleo, no território deste país a empresa brasileira Braspetro já exercia atividades (Silveira 1975b). A política externa, portanto, transbordando o aspecto político, também toca a esfera de poder de um Estado no cenário internacional. As relações políticas entre o governo brasileiro e os países produtores de petróleo, além de configurarem questões políticas, ou seja, relações entre atores representativos dos Estados-Nações, também portavam o espectro do poder do Estado e a sua projeção no âmbito internacional. Se, como Lessa (1994) destaca, a política externa pragmática de Ernesto Geisel foi impulsionada pela garantia energética, seria pertinente aventarmos que um Estado busca sua suficiência energética não somente com um fim econômico, mas também como uma garantia de poder.

Este poder está ligado à manutenção da independência e soberania do Estado-Nação no cenário global, como o próprio Azeredo da Silveira menciona. É neste sentido que a expansão das relações brasileiras com os países do hemisfério sul, durante o governo Ernesto Geisel, também devem ser interpretadas a partir de um quadro geopolítico no qual as relações externas eram reflexo das necessidades do espaço geográfico do Estado brasileiro. Em outras palavras, o abastecimento energético era uma necessidade também para a preservação do poder brasileiro no cenário internacional e para a manutenção do desenvolvimento nacional. É neste sentido que Wight (2002) observa que as relações entre Estados estão pautadas impreterivelmente pelo equilíbrio de poder. A sobrevivência do Estado, portanto, seria a essência das relações interestatais. 
A partir desta ótica também podemos analisar as relações diplomáticas brasileiras no continente africano. Como apresenta Silveira (1974i), as relações brasileiras com os países da África foram ampliadas a partir de uma orientação estratégica que convergia com os ideais do pragmatismo responsável de retomada do crescimento econômico e garantia da segurança nacional, como observa Nazário (1983). O estabelecimento de postos diplomáticos na África Subsaariana, a revisão da posição brasileira sobre o colonialismo e a aproximação do governo brasileiro com os países africanos de língua portuguesa apontam para uma política externa universalista, como evidencia Cervo (2008).

O documento que relata a assistência brasileira prestada ao Cabo Verde, país lusófono, é também uma evidência histórica importante que notabiliza o valor estratégico das relações brasileiras com os países africanos. Se, por um lado, o governo brasileiro oferecia ao primeiro ministro do país africano assistência nos setores agrícola e alimentício, por outro é necessário que se destaquem:

[...] as raízes históricas comuns, o fato de Cabo Verde ser um país inteiramente lusófono e atlântico - passagem entre o Brasil, a Europa e a África - justificariam um relacionamento especial entre as duas nações. (Silveira 1975c).

Deste modo, o caráter estratégico das diretrizes diplomáticas brasileiras para o continente africano pode ser interpretado não somente a partir de uma ótica política, mas também geopolítica, uma vez que o estreitamento e a expansão das relações diplomáticas com os países da África respondiam não somente a ideais econômicos e políticos, mas materializavam o poder intrínseco ao espaço geográfico brasileiro. Isto significa que o delineamento da política externa brasileira em direção à África respondia a uma projeção de poder inerente ao Estado brasileiro. As necessidades do governo brasileiro expressas nas ações da diplomacia liderada por Azeredo da Silveira mostram-se um reflexo da organização do espaço geográfico brasileiro, reproduzindo no cenário externo as suas necessidades e disposições.

Desta forma, a cooperação técnica do governo brasileiro junto a alguns países africanos, muito mais que um esforço colaborativo entre atores da política externa, referia-se a interesses estratégicos dos estadistas brasileiros, como expressa Silveira (1976c) a Ernesto Geisel na visita de Adolphus Benedict Tolbert, filho do presidente da Libéria e presidente da Comissão de Relações Exteriores daquele país. Este documento explicita o que seria uma das linhas de ação brasileira junto aos países africanos: a concessão de linhas de créditos para a aquisição de máquinas e serviços. 
O que as relações brasileiras com a África podem sugerir é que a política externa fundada em orientações pragmáticas respondia à inevitabilidade do poder como objetivo final de qualquer política externa. Assim, constituindo os Estados-Nações um sistema internacional no qual o poder do Estado é uma condição para a garantia de sua soberania, como evidencia Wight (2002), é possível vislumbrar que a ótica externa do governo brasileiro durante o pragmatismo responsável partia do pressuposto de manutenção e multiplicação do poder do Estado brasileiro.

A política externa brasileira durante o pragmatismo responsável para com o continente africano pode ser analisada sob duas perspectivas. A primeira pressupõe a África como um continente apto a fornecer posições favoráveis ao governo brasileiro em relação ao campo energético, e a segunda estabelece que o continente africano possuía uma importância estratégica em termos de posição geográfica. Sob esta última ótica, o estímulo de relações entre o governo brasileiro e os governos de alguns países africanos, principalmente aqueles de língua portuguesa, também dialogam com a perspectiva de expansão do poder do Estado brasileiro, em que a pujança econômica, militar, técnica e cultural do Brasil permitia ao governo militar a afirmação dos interesses atribuídos pelo Estado brasileiro a outras áreas do globo.

O governo de Ernesto Geisel, a partir de uma agenda pragmática, procurou afirmar seus interesses em âmbitos não anteriormente usuais, como demonstramos no caso da África e da China. Além destes países, Cuba representa um caso interessante de importância política e estratégica, já que, além de estar sob o regime socialista, localizava-se numa área adjacente à América do Sul que representava um entreposto importante para o fluxo comercial marítimo mundial, como aponta Mattos (1977).

De 1962 até o final desta década, foram tomadas medidas contrárias ao governo cubano no âmbito da Organização dos Estados Americanos (OEA). ${ }^{9}$ A partir da década de 1970, alguns países da América Latina e Caribe começaram a retomar as relações com o governo de Havana. Estas informações são expostas por Silveira (1974l), sobressaltando que as ações da política externa brasileira eram tomadas após o levantamento de informações de outros Estados. O adjetivo "responsável”, portanto, referia-se ao fato de que, embora o governo brasileiro tratasse com Estados ideologicamente opostos às convicções dos estadistas do país, era possível que acordos fossem estabelecidos devido, inclusive, a uma análise conjuntural do país com o qual a diplomacia brasileira fosse tratar.

Muito embora as relações diplomáticas entre Brasil e Cuba não tenham sido restabelecidas durante o governo Ernesto Geisel, é possível identificar, por meio dos documentos, a relação entre a expansão do poder brasi- 
leiro e a política externa. No documento de Silveira (1974m) é identificável o interesse de setores empresariais brasileiros em expandir suas exportações em direção ao país caribenho. Também é possível verificar que o fato de que empresários argentinos já mantivessem relações com Cuba era uma circunstância que incomodava os atores externos da diplomacia brasileira.

A manutenção do distanciamento do governo brasileiro em relação a Cuba pode ser explicada pela continuidade do respeito dos estadistas brasileiros ao poder dos Estados Unidos. As diversas consultas sobre as problemáticas envolvendo Cuba destacam os limites da autonomia do governo Ernesto Geisel que, mesmo dispondo de um mercado econômico promissor no país caribenho e um possível colaborador para a expansão da influência brasileira na região, mantinham minimamente o acatamento a certas posições do governo norte-americano no cenário regional. Como comprovação deste fato, dentre os diversos documentos podemos citar os subsídios teóricos que precederam a visita do secretário de Estado norte-americano Henry Kissinger ao Brasil. Nestes, Azeredo da Silveira observa que:

o Brasil aceita que os EUA tenham, por sua própria capacidade operativa, o papel de líder do mundo ocidental. Vê esse papel, porém, no seu contexto ético. Não aceita, por outro lado, que a liderança se divorcie da ética e se transforme em comando (Silveira 1976d).

Neste sentido, a política externa brasileira direcionada à América Central e ao Caribe, considerando a relação entre o governo brasileiro e o cubano, serve-nos de indícios de que o governo Ernesto Geisel primou por uma política externa de distanciamento cauteloso em relação aos Estados Unidos, principalmente em territórios nos quais este país exercia maior influência e estrategicamente era uma área de risco, como era o Caribe.

\section{CONCLUSÃO}

A partir dos documentos diplomáticos, é possível identificar que a política externa brasileira durante os anos de 1974 a 1979 não esteve restrita a trâmites somente de caráter político. Durante o pragmatismo ecumênico responsável, é verificável que as estratégias externas do governo brasileiro estavam sustentadas por uma percepção do espaço geográfico nacional e da possibilidade de inserção autônoma do Brasil num cenário global polarizado.

No âmbito regional, notabilizam-se os esforços do governo Ernesto Geisel em afirmar a posição brasileira de liderança continental. Deste modo, é possível identificar claramente a visão do Presidente referente ao liame entre a construção de infraestruturas entre o Brasil e os Estados 
vizinhos e a consolidação do poder brasileiro na esfera sul-americana. A partir das substantivas relações construídas pelo governo Ernesto Geisel no Cone Sul, como o financiamento para a implantação de um sistema viário tanto na Bolívia quanto no Paraguai, a venda de armamentos, os empréstimos concedidos e um plano de acesso ao Oceano Atlântico, fazia-se pender a balança de poder sul-americano a favor do Brasil, como inclusive verifica Mello (1996).

Embora sem conexões terrestres, o governo brasileiro também efetivou uma diplomacia aproximativa em relação aos países do continente africano, principalmente em relação àqueles que possuíam uma significativa produção de petróleo e que, deste modo, representavam uma alternativa à matéria prima que derivava principalmente do Oriente Médio. A elevação do preço do petróleo no mercado internacional colocou em xeque o desenvolvimento econômico brasileiro e, diante desta conjuntura, o governo brasileiro imprimiu à política externa brasileira não somente acordos políticos, mas, antes de tudo, teria a suas diretrizes externas consoantes às condições espaciais do território nacional brasileiro. Neste sentido, é possível identificar o peso das condições territoriais brasileiras e o delineamento da política externa do país.

A estratégia da política externa brasileira, portanto, antes de tudo constituiu-se a partir de uma visão geopolítica, que, no entanto, não coincide exatamente com os projetos geopolíticos definidos por Travassos (1935) ou Silva (1981). A geopolítica, como apontam os documentos da política externa brasileira, transcende esta concepção de teses a serem aplicadas ao território e demonstram que os próprios atores do Ministério das Relações Exteriores do Brasil ponderavam sobre as necessidades do espaço geográfico brasileiro e a representação de poder do Estado-Nação no cenário externo. Portanto, é necessário dizer que o pragmatismo ecumênico responsável - considerando que as relações entre os estados eram orientadas por uma disputa de poder — não foi somente uma forma política de condução do Estado brasileiro pelo governo Ernesto Geisel. A visão deste governo, de que a perspectiva externa do país deveria ser elaborada para satisfazer previamente os interesses atribuídos ao Estado, está atrelada a uma geopolítica permanente que emana das próprias condições do espaço geográfico do Estado. Assim, o desenvolvimento do território brasileiro e a projeção de poder do Brasil no cenário internacional são elementos indispensáveis para a definição de qualquer estratégia de política externa deste país, de modo que, a nosso ver, a construção da política externa de Ernesto Geisel, sob os moldes do pragmatismo responsável, era, antes de tudo, uma geopolítica desse governo. 


\section{REFERÊNCIAS}

Aron, Raymond. 2002. Paz e guerra entre as nações. Brasília: Universidade de Brasília.

Aróstegui, Julio. 2006. A pesquisa histórica: teoria e método. Bauru: Editora da Universidade do Sagrado Coração.

Arruda, Antônio de. 1980. ESG: história de sua Doutrina. São Paulo: GRD; Brasília: INL.

Becker, Bertha K. 2012a. "A Geografia e o Resgate da Geopolítica”. Espaço Aberto 2, no. 1 (Jul.): 117-150, https://revistas.ufrj.br/index.php/EspacoAberto/article/view/2079/1846.

2012b. Manual do candidato: geografia. Brasília: FUNAG.

Castro, Therezinha de. 1999. Geopolítica: princípios, meios e fins. Rio de Janeiro: Biblioteca do Exército.

Cervo, Amado Luiz. 1994. "Relações Internacionais do Brasil". In Cervo, Amado L. (Org.). O desafio internacional: a política exterior do Brasil de 1930 aos nossos dias. Brasília: EDUNB.

2003. "Política exterior e relações internacionais do Brasil: enfoque paradigmático". Revista brasileira de política internacional 46, no. 2 (Dez.): 5-25, Dez. http://www.scielo.br/scielo.php? script=sci_arttext\&pid=So034$73292003000200001 \& \operatorname{lng}=$ en\&nrm=iso.

Saraiva.

2008. Inserção internacional: formação dos conceitos brasileiros. São Paulo:

Child, Jack, and Philip Kelly. 1998. Geopolitics of the Southern Cone and Antarctica. Boulder: L. Rienner.

Costa, Wanderley Messias da. 2008 Geografia política e geopolítica: discursos sobre oterritório e o poder. São Paulo: EdUSP.

Escola Superior de Guerra. 1975. Relatório de Viagem América I. Arquivo da ESG. TGV9-75/América I.

Guimaraes, Samuel Pinheiro. 2008. "Nação, nacionalismo, Estado”. Estudos avançados 22, no. 62 (Abr.): 145-159. http://www.scielo.br/scielo.php?script=sci_arttext\&pid=So103-40142008000100010\&lng=pt\&nrm=iso. 
Leite, Patrícia Soares. 2011. O Brasil e a Cooperação Sul-Sul em Três Momentos de Política Externa: os governos Jânio Quadros/João Goulart, Ernesto Geisel e Luiz Inácio Lula da Silva. Brasília: Fundação Alexandre de Gusmão.

Lessa, Antônio Carlos. 1994. "Brasil, Estados Unidos e Europa Ocidental no contexto do nacional-desenvolvimentismo: estratégias de diversificação de parcerias, 1974-1979”. Dissertação (Mestrado), Universidade de Brasília, Instituto de Relações Internacionais, Brasília.

. 1998. "A diplomacia universalista do Brasil: a construção do sistema contemporâneo de relações bilaterais". Revista brasileira de política internacional 41, s/n.: 29-41. http://www.scielo.br/scielo.php? script=sci_arttext\&pid=So034$73291998000300003 \& \operatorname{lng}=\mathrm{en} \& n \mathrm{~nm}=$ isso.

Mackinder, Halford. 1904. The Geographic Pivot of History 4, no. 23 (Abr.): 421444. https://archive.org/stream/1904HEARTLANDTHEORYHALFORDMACKINDER/190 4\%2OHEARTLAND\%2OTHEORY\%2OHALFORD\%20 MACKINDER_djvu.txt.

Madruga, Francisco José Stanzione. 1978. Análise da Conjuntura Externa. TG5-78, subgrupo 2 (Setembro).

Mahan, Alfred Thayer. 1897. The Interest of America in Sea Power, Present and Future. Londres: Sampson Low, Marston \& Company. http://onlinebooks.library. upenn.edu/webbin/gutbook/lookup? num $=15749$.

Mattos, Carlos de Meira. 1997. A Geopolítica e as Projeções do Poder. Rio de Janeiro: Bibliex.

Mello, Leonel Itassu Almeida. 1996. Argentina e Brasil: A balança de poder no Cone Sul. São Paulo: Annablume.

Ministério dos Transportes. 1975. Informações Multinacionais Brasil-Paraguai. 13 de fevereiro, s/n. Acervo EG pr 1974.03.26/1.

Moura, Gerson. 1980. Autonomia na dependência: a política externa brasileira de 1935 a 1942. Rio de Janeiro: Nova Fronteira.

Nazário, Olga. 1983. "Pragmatism in Brazilian Foreign Policy: The Geisel Years, 1974-1979”. Dissertação (Mestrado), University of Miami.

Nunes, Tiago Estivallet. 2012. "Política externa brasileira para América Central e Caribe (1995-2010): a ampliação das esferas de influência de uma potência média emergente”. Dissertação (Mestrado). Porto Alegre/RS: Universidade Federal do Rio Grande do Sul, Departamento de Ciências Políticas. 
Pereira, Carlos Patrício Freitas. 2007. Geopolítica e o Futuro do Brasil: Amazônia Ocidental e Pantanal Comunidade Sul-Americana. Rio de Janeiro: Biblioteca do Exército.

Silva, Golbery do Couto. 1974. Posição favorável de Golbery do Couto e Silva pelo Reconhecimento da China. Aviso de Golbery do Couto e Silva ao presidente Ernesto Geisel, secreto, nº 165/74, 18 de abril, Ernesto Geisel (EG) pr 1974.03.00/2.

1981. Conjuntura Política Nacional: O Poder Executivo e Geopolítico do Brasil. Rio de Janeiro: Livraria José Olympio.

Silveira, Antonio Azeredo da. 1974a. Relações Brasil-Paraguai, tratado de Itaipu. Informação para o Senhor Presidente da República. Síntese dos assuntos, secreto, 14 de maio, $n^{\circ}$ 91. AAS mre d 1974.03.26.

1974b. Inauguração da Agência do Estado de São Paulo. Informação para o Senhor Presidente da República, Lembrete, 8 de março de 1977, nº 61. AAS mre d 1974.03.26.

1974c. Grupo interministerial para a exportação de armamentos. Informação para o Senhor Presidente da República, anexo 3, secreto, 26 de março, $n^{\circ} 25$. AAS mre d 1974.03.26.

1974d. Problema da mediterraneidade da Bolívia. Informação de Antonio Azeredo da Silveira para o Senhor Presidente da República. Declaração Conjunta, confidencial, 30 de abril, $\mathrm{n}^{\circ}$ 72. AAS mre d 1974.03.26.

1974e. Fornecimento de Granadas à Bolívia. Informação para o Senhor Presidente da República, secreto, 8 de agosto, n 192. AAS mre d 1974.03.26.

1974f. Aproveitamento de Recursos Naturais. Informação para o Senhor Presidente da República, secreto, 21 de novembro, nº 284, AAS mre d 1974.03.26.

1974g. O Brasil e a República Popular da China. Informação de Antônio Azeredo da Silveira para o Senhor Presidente da República, secreto, 26 de março, $\mathrm{n}^{\circ}$ 24. Azeredo da Silveira (ASS) AAS mre d 1974.03.26.

1974h. Contrato de fornecimento de açúcar a longo prazo. Informação de Antônio Azeredo da Silveira para o Senhor Presidente da República, intercâmbio comercial com a República Popular da China. 10 de outubro, $n^{\circ}$ 244. Azeredo da Silveira (ASS) AAS mre d 1974.03.26.

1974i. Ampliação da rede de postos diplomáticos na África-subsaariana. Informação de Antônio Azeredo da Silveira para o Senhor, 6 de agosto, ${ }^{\circ} 187$. Ernesto Geisel (EG) pr 1974.03.00/2. 
1974j. Visita do presidente da Costa do Marfim. Informação de Antônio Azeredo da Silveira para o Senhor Presidente da República, 6 de maio, $n^{\circ} 79$. Ernesto Geisel (EG) pr 1974.03.00/2.

1974l. Visita do presidente Echeverria ao Brasil. Informação de Antônio Azeredo da Silveira para o Senhor Presidente da República, 19 de julho, no 170. Acervo Azeredo da Silveira (AAS) mre d 1974.03.26.

- 1974m. Interesse da Saab-Scania do Brasil S.A. Informação de Antônio Azeredo da Silveira para o Senhor Presidente da República, exportações para Cuba., secreto, 22 de abril, nº 49. Ernesto Geisel (EG) pr 1974.03.00/2.

1975a. A questão da Palestina e a posição do Brasil na XXX assembleia geral das nações unidas. Informação de Antônio Azeredo da Silveira para o Senhor Presidente da República, secreto, 13 de novembro, nº 309. Ernesto Geisel (EG) pr 1974.03.00/2.

1975b. Cooperação econômica com o Iraque Informação de Antônio Azeredo da Silveira para o Senhor Presidente da República, secreto, 10 de julho, nº 211. Ernesto Geisel (EG) pr 1974.03.00/2.

. 1975c. Assistência à Cabo Verde Informação de Antônio Azeredo da Silveira para o Senhor Presidente da República. Visita do primeiro ministro Pedro Pires ao Brasil, confidencial, 4 de setembro, ${ }^{\circ}$ 255. Ernesto Geisel (EG) pr 1974.03.00/2.

. 1976a. Informação para o Senhor Presidente da República. Secreto, 24 de setembro, no 310 . Ernesto Geisel (EG pr) 1974.03.00/2.

1976b. Relações Brasil-Paraguai-Argentina. Telegrama à embaixada brasileira em Assunção, secreto-exclusivo, 16 de agosto, $n^{\circ}$ 91, Acervo Azeredo da Silveira (AAS) mre d 1974.04.23.

1976c. Visita ao Brasil do Senhor Adolphus Benedict Tolbert. Informação de Antônio Azeredo da Silveira para o Senhor Presidente da República, 5 de fevereiro, $n^{\circ}$ 54. Ernesto Geisel (EG) pr 1974.03.00/2.

1976d. Subsídios para conversações com o secretário de Estado Henry Kissinger Informação de Antônio Azeredo da Silveira para o Senhor Presidente da República, 13 de fevereiro, $\mathrm{n}^{\circ}$ 61. Acervo Azeredo da Silveira (AAS) mre d 1974.03.26.

Spektor, Matias. 2004. “Origens e direção do Pragmatismo Ecumênico e Responsável (1974-1979)”. Rev.bras.polit.int.47,no.2(Dez.):191-222.http://www.scielo.br/scielo.php? script=sci_arttext\&pid=So034-73292004000200007\&lng=en\&nrm=iso. 
Spykman, N. 1938. Geography and Foreign Policy, II. The American Political Science Review, 32(2), 213-236. doi:10.2307/1948667

Travassos, Mario. 1935. Projeção continental do brasil. São Paulo, SP: Companhia Editora Nacional.

Vizentini, Paulo Gilberto Fagundes. 1998. Política externa do regime militar brasileiro: Multilateralização, desenvolvimento e construção de uma potência média (1964-1985). Porto Alegre: Ed. UFRGS.

Wight, Martin. 2002. A política do poder. Brasília: Editora Universidade de Brasília. 


\section{NOTAS}

1. Segundo Guimarães (2008, 145), "Nacionalismo é, também, o desejo de afirmação e de independência política diante de um Estado estrangeiro opressor ou, quando o Estado já se tornou independente, o desejo de assegurar em seu território um tratamento melhor pelo Estado, ou pelo menos igual ao tratamento concedido ao estrangeiro, seja ele pessoa física seja jurídica.".

2. Na década de 1970, os Estados Unidos começavam a demonstrar incapacidade em conduzir a Guerra do Vietnã, iniciada em 1955. Além disso, em 1974, o presidente Richard Nixon era julgado pelo escândalo de Watergate, denunciado em 1972. Esta conjuntura constataria certa dificuldade do governo dos Estados Unidos em tutelar seus interesses no âmbito externo. Para o governo Ernesto Geisel, isto significava certa margem de autonomia para a política externa brasileira.

3. Reforçando a proposição de Pereira (2007), é possível verificar, segundo Spykman (1938, 43, tradução nossa), que "Deveria também ser lembrado que o significado de uma dada localização é tanto um fator na política externa de um determinado Estado como o resultado da história passada do mesmo Estado".

4. Emílio Garrastazu Médici, presidente do Brasil entre 1969 a 1974.

5. Segundo Aron (2002, 153), "o sistema internacional é o conjunto constituído pelas unidades políticas que mantêm relações regulares entre si e que são suscetíveis de entrar numa guerra geral.”. Esta visão de Aron dialoga com a concepção realista de que o ambiente global, composto por Estados-Nações com múltiplos interesses, organiza-se de forma anárquica, na qual a segurança global sustenta-se por uma relação de poder, ideologia e força.

6. Sinteticamente, define Cervo (2008, 224): "Entre 1930 e 1989 a política exterior do Brasil foi atrelada ao processo de desenvolvimento nacional”.

7. Durante a Guerra Fria, os países do primeiro mundo referiam-se aos países da Europa Capitalista, Estados Unidos, Canadá, Japão e Austrália. Os países do segundo mundo eram os países do bloco comunista e os países do terceiro mundo referia-se aos países não alinhados a nenhum dos dois blocos.

8. O sionismo é um movimento social que está associado à criação e consolidação de um Estado para o povo judeu, no caso, de Israel.

9. A Organização dos Estados Americanos foi fundada em 1948, contando hoje com a participação de 35 países. No interior da organização ocorrem reuniões e assembleias para a discussão de assuntos que envolvam o continente americano. Para mais informações, consultar http://www. oas.org/pt/. 


\section{RESUMO}

Este artigo analisa a geopolítica e a política externa durante o governo de Ernesto Geisel a partir de documentos da diplomacia brasileira, apontando a existência de um pensamento geopolítico da política externa originada no próprio Ministério das Relações Exteriores. Para isto, exploramos as relações externas brasileiras no Cone Sul, África, Oriente Médio, China e Cuba a partir de documentos da política externa brasileira disponíveis no Centro de Pesquisa e Documentação de História Contemporânea do Brasil (CPDOC), além da análise de documentos da Escola Superior de Guerra (ESG).

Palavras-Chave: Geopolítica; Pragmatismo; Ernesto Geisel; Política Externa.

\section{ABSTRACT}

This article analyzes the geopolitics and the foreign policy during the government of Ernesto Geisel, from documents of Brazilian diplomacy, pointing out the existence of a geopolitical thought in the foreign policy originated in the Ministry of Foreign Relations itself. For this the Brazilian foreign relations in the Southern Cone, Africa, Middle East, China and Cuba was researched from documents of Brazilian foreign policy available at the Center for Research and Documentation of Contemporary History of Brazil (CPDOC), in addition to the analysis of documents from the Higher School of War (ESG).

Keywords: Geopolitics; Pragmatism; Ernesto Geisel; Foreign Policy. 